\title{
Defining Cut-off Scores for MMSE in an Educated and Illiterate Arabic Speaking Egyptian Elderly Population
}

Nehal EIKholy ${ }^{1}$, Tawfik HM${ }^{1}$, Ebeid $S^{1}$, Hamza SA ${ }^{1}$, Madkor ORE ${ }^{2}$

1 Geriatrics \& Gerontology, Faculty of Medicine, Ain-Shams University

2 Geriatric psychologist fellow, Ain-Shams University

\section{Abstract}

Background: Dementia prevalence is increasing, becoming a public health problem in geriatric population requiring early diagnosis. The MMSE is the most commonly used screening method in the diagnosis and assessment of dementia severity in clinical and research fields; however cut off points in Egyptian population with its different levels of education are not clear.

Aim: To review MMSE cut-off values adjusted for schooling in an Arabic speaking sample of Egyptian elderly.

Methods: The study was conducted on 159 male and female community-dwelling participants aged $\geq 60$ years, cutoff points were determined according to DSM-IV criteria for dementia after defining the participants according to their level of education.

Results: Overall the sample, the cut-off score of MMSE for diagnosing dementia was 23 points (sensitivity $=95 \%$, specificity $=73.83 \%$ ). For participants with $>9$ years education cut off point was $\leq 22$ (sensitivity $=94 \%$, specificity $=70.2 \%$ ) while for those with for participants $\leq 9$ years education cut off point was $\leq 21$ (sensitivity= $91 \%$, specificity=33.3\%).

Conclusions: New cut off points for MMSE became now available for both educated and low educated geriatric people. The new cut-off scores are $\leq 22$ for subjects $>9$ years education and $\leq 21$ for illiterate subjects and those with $<9$ years education.

Keywords: Dementia - MMSE- elderly- Egyptians

\section{Background}

With aging of the population dementia became a public health problem increasing health care costs. It affects about $5-10 \%$ of elderly population above the age of 65 with doubling prevalence each 5 years till reaching about $50 \%$ at the age of $85^{1,2}$.

The Mini-Mental State Examination (MMSE) was published in 1975 as a practical method to assess cognitive functions. Although it has some advantages as it is affected by age and education and does not measure executive function, indeed it is the most commonly used screening method in the assessment of the severity of dementia in clinical and research fields and for longitudinal follow up of patients. Researchers stated that most of the healthcare professionals use the MMSE and its variants during their medical practice ${ }^{3,4}$. MMSE has several strengths including that it can be quickly administered in clinical interview and research settings. It has demonstrated utility in its widespread and long-standing use in cognitive screening. The test largely meets its goals as a screening tool of cognitive function and serial measurement of cognitive changes 5 . The maximum score for MMSE is 30, with lower scores indicating more severe cognitive problems. The cut point established for the MMSE defines 'normal' cognitive function and is usually set at $24{ }^{6}$. However, these scores need to be adjusted according to age, 
education, and ethnicity ${ }^{7}$.

There is no universally accepted cut-point based on age and education level. The most commonly reported cutpoints were $23 / 24$ and $24 / 25^{8}$. Only one study in Egypt ${ }^{9}$ determined the effect of education on MMSE score with no overall cutoff points for the test or for highly educated group of population. There are questions about the accuracy of scores of MMSE in illiterate and low educated people; as false positive results may lead to classifying normal illiterate people to have cognitive impairment ${ }^{10}$, implicating the need for modification in the test for illiterate and low educated geriatric population.

The Diagnostic and statistical Manual IV (DSM IV) focuses on a categorical approach in spite of the difficulty in differentiating "normal" from "pathological" impairment at certain ages ${ }^{11}$

The study aimed to define cutoff points of MMSE for diagnosing dementia in Egyptian elderly illiterate and educated people.

\section{Methods}

Cross sectional study where 159 of community dwelling elderly were recruited from: relatives of patients in the geriatric and ophthalmology wards, patients attending geriatrics outpatient clinic and geriatric clubs.

\section{Inclusion criteria:}

- Arabic speaking males and females aged 60 years or more.

-Oral consent was taken from all participants.

\section{Exclusion criteria:}

-Subjects who refused to participate in the study.

Measures

\section{I) MMSE}

-The 30 points-scale was administered evaluating orientation, registration, attention and calculation, recall, language (repetition and complex command) and visuospatial functions ${ }^{3}$

- Modifications were done in item of calculation using reversed days of the week (instead of serial $7 \mathrm{~s}$ subtractions starting from 100) in illiterate people, people who can only read and write and those with primary school education.

\section{II) DSM IV criteria for dementia}

-According to the American Psychiatric Association Diagnostic and Statistical Manual of Mental Disorders IV (DSM-IV) participants were asked about the presence of

1) Memory impairment plus at least one of the followings:

2) Aphasia, apraxia, agnosia or disturbance in executive functioning.

- Participant were considered positive for dementia if the above domains were positive, affecting them socially or functionally and after the exclusion of having delirium at the present time.
Table 1: MMSE Indices (Cut off point, Sensitivity and Specificity) with DSMIV for Dementia

\begin{tabular}{|c|c|c|c|c|}
\hline Area & $\begin{array}{c}\text { Std. } \\
\text { Error }\end{array}$ & $\begin{array}{c}\text { Asymptotic } \\
\text { Sig. }\end{array}$ & $\begin{array}{l}\text { Asymptotic 95\% } \\
\text { Confidence Interval }\end{array}$ \\
\cline { 3 - 5 } & & & Lower Bound & $\begin{array}{c}\text { Upper } \\
\text { Bound }\end{array}$ \\
\hline $\mathbf{0 . 7 6}$ & 0.037 & 0.000 & 0.69 & 0.83 \\
\hline \multicolumn{4}{|c|}{ Cut off point } & \multicolumn{2}{|c|}{23} \\
\hline \multicolumn{3}{|c|}{ Sensitivity } & $95 \%$ \\
\hline \multicolumn{3}{|c|}{ Specificity } & $73.83 \%$ \\
\hline Positive Predictive Value (PPV) & $44.03 \%$ \\
\hline Negative Predictive Value (NPV) & $95.70 \%$ \\
\hline
\end{tabular}

Figure 1: ROC Curve demonstrating sensitivity and specificity of MMSE cut-off points

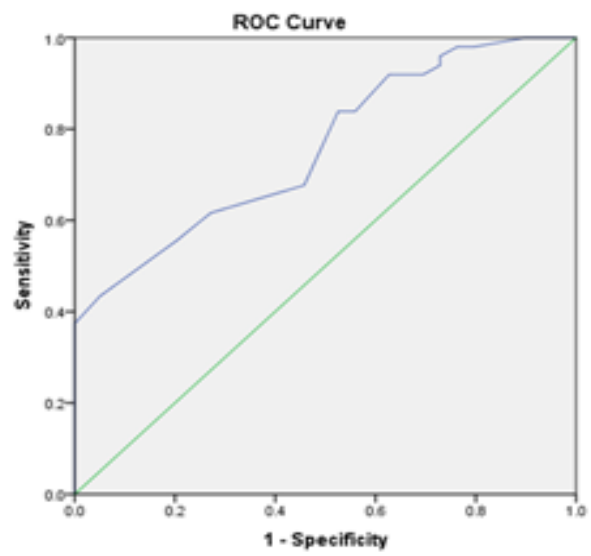

It was used as the standard test for diagnosing dementia with results of MMSE correlated to DSM IV results. Statistical Analysis

The statistical analysis was carried out with the Statistical Package for the Social Sciences for Windows version 16.0 (SPSS Inc., Chicago, IL, USA.). Sensitivity, specificity, positive and negative predictive values, and their 95\% confidence interval levels for cutoff points were calculated for MMSE. ROC curve was conducted to determine MMSE cut off points.

\section{Results}

159 community dwelling elderly were recruited, both cognitively intact and impaired. Participants included 58 illiterate and low educated ( $\leq 9$ years education) and 101 with higher education ( $>9$ years education). Some participants had clinical diagnosis; 10 vascular cognitive impairment, 5 traumatic brain injuries, 3 Alzheimer's disease, 1 behavioral frontotemporal dementia, 1 posterior cortical atrophy, 3 space occupying lesion, 2 carbon monoxide poisoning, 3 post arrest. Table 1 shows cutoff points of MMSE was 23 out of 30 for diagnosing dementia in the whole sample with sensitivity of $95 \%$, specificity of $73.83 \%$, positive predictive value (PPV) $44.03 \%$ and negative predictive 
$\begin{array}{lll}\text { value } & (\mathrm{NPV}) & 95.70 \% .\end{array}$
Table (2) MMSE Indices (Cut off point, Sensitivity and Specificity) with DSMIV for Dementia in illiterates and low educated $(\mathrm{N}=58)$

\begin{tabular}{|c|c|c|c|c|}
\hline \multirow[t]{2}{*}{ Area } & \multirow[t]{2}{*}{$\begin{array}{l}\text { Std. } \\
\text { Error }\end{array}$} & \multirow[t]{2}{*}{$\begin{array}{l}\text { Asymp } \\
\text { Sig. }\end{array}$} & \multicolumn{2}{|c|}{$\begin{array}{l}\text { Asymptotic } 95 \% \\
\text { Confidence Interval }\end{array}$} \\
\hline & & & Lower Bound & $\begin{array}{l}\text { Upper } \\
\text { Bound }\end{array}$ \\
\hline 0.88 & 0.050 & 0.000 & 0.79 & 0.98 \\
\hline \multicolumn{3}{|c|}{ Cut off point } & \multicolumn{2}{|l|}{21} \\
\hline \multicolumn{3}{|l|}{ Sensitivity } & \multicolumn{2}{|l|}{$91 \%$} \\
\hline
\end{tabular}

Table 3: MMSE Indices (Cut off point, Sensitivity and Specificity) with DSMIV for Dementia in educated $(\mathrm{N}=101)$.

\begin{tabular}{|c|c|c|c|c|}
\hline Area & Std. & Asymp & \multicolumn{2}{|c|}{ Asymptotic 95\% Confidence Interval } \\
\cline { 4 - 5 } & Error & Sig. & Lower Bound & Upper Bound \\
\hline 0.88 & $\mathbf{0 . 0 5 0}$ & $\mathbf{0 . 0 0 0}$ & $\mathbf{0 . 7 8}$ & $\mathbf{0 . 9 7}$ \\
\hline \multicolumn{3}{|c|}{ Cut off point } & \multicolumn{2}{|c|}{$\mathbf{9 4 \%}$} \\
\hline \multicolumn{3}{|c|}{ Sensitivity } & \multicolumn{2}{|c|}{$\mathbf{7 0 . 2 \%}$} \\
\hline \multicolumn{3}{|c|}{ Specificity }
\end{tabular}

Figure 1 shows ROC curve for sensitivity and specificity of MMSE cutoff points. The cutoff of points in illiterate and low educated people as shown in Table 2 was $\leq 21$ with $91 \%$ sensitivity and $33.3 \%$ specificity. Table 3 shows cutoff points in high educated people was $\leq 22$ with $94 \%$ sensitivity and $70.2 \%$ specificity.

\section{Discussion}

MMSE is one of the most widely used tests for cognitive screening all over the world and though conflicts exist regarding its accuracy; the American Academy of Neurology in its guidance and the Alzheimer's Association in their guidance suggested MMSE as an important tool for cognitive screening ${ }^{12 .}$ Though MMSE is widely used in Egypt, there are no cutoff points for diagnosing dementia in Egyptian population. It is difficult to use the same measures and cutoff points used worldwide because of the difference in educational and cultural background. Cut off points, sensitivity, specificity, positive predictive value, and negative predictive value were calculated for the MMSE according to DSMIV criteria for dementia.

However, regarding level of education; the cut-off points of the current study were $\leq 22$ for participant $>9$ years of education (sensitivity $=94 \%$, specificity $=70.2 \%$ ) and $\leq 21$ for participants $\leq 9$ years of education (sensitivity $=91 \%$, specificity $=33.3 \%$ ), nearly the same cut-off points in the study conducted by Kochhann and colleges in 2010 (13) which were 21 for the illiterate group (sensitivity=93\%, specificity=82\%), 22 for the low education group (sensitivity $=87 \%$, specificity $=82 \%$ ), 23 for the middle education group (sensitivity $=86 \%$, specificity=87\%) and 24 for the high education group (sensitivity=81\%, specificity $=87 \%$ ). The study carried out by Kochhann and colleges in $\mathbf{2 0 1 0}$ was able to stratify their sample into 4 levels of education with 4 cut-off points, which could be contributed by their large study sample 968 participants in comparison with 159 participants in the current study.

\section{Conclusion}

This is the first study in Egypt to define cutoff points for diagnosis of dementia using MMSE in illiterate and educated geriatric people. The new cut-off scores are $\leq 22$ for subjects $>9$ years education and $\leq 21$ for illiterate subjects and those $<9$.

\section{References}

1-Administration on Aging, Department of Health and Human Services. Aging statistics. Last modified May 8, 2013. Available from: http://www.aoa.gov/AoA Root/Aging_Statistics/index.aspx. Accessed May 17, 2013.

2. Mohs RC, Breitner JC, Silverman JM, Davis KL. Alzheimer's disease. morbid risk among first-degree relatives approximates $50 \%$ by 90 years of age. Arch Gen Psychiatry 1987; 44:405- 8.

3- Folstein MF, Folstein SE, McHugh PR. "mini-mental state." a practical method for grading the cognitive state of patients for the clinician. J Psychiatr Res. 1975; 12:189-98.

4- Ciesielska N, Sokołowski R, Mazur E, Podhorecka M, Polak-Szabela A, Kędziora-Kornatowska K. Is the Montreal Cognitive Assessment (MoCA) test better suited than the Mini-Mental State Examination (MMSE) in mild cognitive impairment $(\mathrm{MCl})$ detection among people aged over 60? Meta-analysis. Psychiatr. Pol.2016; 50(5): 1039-1052.

5- Bernard BA, Goldman JG. MMSE - Mini-Mental State Examination. Encyclopedia of Movement Disorders. 2010; P 187-189.

6- Creavin ST, Wisniewski S, Noel-Storr AH, Trevelyan CM, Hampton T, Rayment D, Thom VM, Nash KJ, Elhamoui H, Milligan R, Patel AS, Tsivos DV, Wing T, Phillips E, Kellman SM, Shackleton HL, Singleton GF, Neale BE, Watton ME, Cullum S. Mini-Mental State Examination (MMSE) for the detection of dementia in people aged over 65. Cochrane Database Syst Rev. 2016; Jan 13; (1):CD011145.

7- Shim YS, Yang DW, Kim HJ et al, Park YH, Kim S. Characteristic differences in the mini-mental state examination used in Asian countries. BMC Neurol. 2017; $17: 141$.

8- Lin JS, O'Connor E, Rossom RC et al, Perdue LA1, Burda BU1, Thompson M1, Eckstrom E. Screening for Cognitive Impairment in Older Adults: An Evidence Update for the U.S. Preventive Services Task Force. Evidence Synthesis. 2013; No 107.

9- Sweed HS, Abd-Al-Atty MF, El-Banouby SM, Mortagy AK. Education effect on Mini-Mental status Examination among Egyptian Elderly. Middle East age\& aging 2009; 6(4).

10- Fillenbaum G, Heyman A, Williams K, Prosnitz B, Burchett B. Sensitivity and specificity of standardized screens of cognitive impairment and dementia among elderly black and white community residents. J Clin Epidemiol. 1990; 43:651- 60 .

11- Domenech JP, Artigas PA. Dementia DSM-IV/ICD-10 or neurocognitive disorder DSM-5? Eur. J. Psychiat. 2015; vol.29 no.1.

12- Mitchell AJ. A meta-analysis of the accuracy of the mini-mental state examination in the detection of dementia and mild cognitive impairment. J. Psychiatr. Res. 2009; 43: 411-431.

13- Kochhann R, Varela JS, Lisboa CSM, Chaves MLF. The Mini Mental State Examination: Review of cutoff points adjusted for schooling in a large Southern Brazilian sample. Dement Neuropsychol. 2010; 4(1):35-41. 